\title{
Once-Only Principle Good Practices in Europe
}

\author{
Maria A. Wimmer ${ }^{(凶)}$ (D) \\ University of Koblenz-Landau, Universitätsstr. 1, 56070 Koblenz, Germany \\ wimmer@uni-koblenz.de
}

\begin{abstract}
Digital transformation has become a recent keyword in the evolution of public sector modernization through the once-only principle (OOP). The onceonly principle is among the seven driving principles in the eGovernment Action Plan 2016-2020 of the European Commission (EC). It requires that citizens and businesses need not to provide the same data to governments if that data is already in their hands. The ultimate goal of the principle is to reduce administrative burden and to simplify public service provisioning therewith also reducing costs and improving public service. To boost developments towards administrative burden reduction and simplification in public service provisioning, the SCOOP4C project has investigated good practice solutions across Europe. In this contribution, we provide an overview of good practice OOP cases and OOP enablers studied in the project, followed by a synthesis of the benefits and key enablers to boost the OOP implementation across Europe.
\end{abstract}

Keywords: Once-only principle · OOP · Good practices · OOP cases · OOP enablers

\section{Introduction}

The eGovernment Action Plan 2016-2020 of the European Union (EU) commits Member States to modernize public services along seven principles of public sector transformation in order to contribute to economic growth, jobs as well as sustainable and resilient societies [16]. The vision of the EU Member States set in this strategic document is that "by 2020, public administrations and public institutions in the European Union (EU) should be open, efficient and inclusive, providing borderless, personalized, user-friendly, end-to-end digital public services to all citizens and businesses in the EU" [16]. The Action Plan requires new and innovative concepts to design and deliver improved public services that better meet the needs of citizens and businesses.

The Once Only Principle (OOP) is among the seven underlying principles of this action plan to make government more effective and simpler and to reduce administrative burdens by asking citizens and companies to provide certain (standard) information to the public authorities only once. Public authorities are required to "take action if permitted to internally re-use this data, in due respect of data protection rules, so that no additional burden falls on citizens and businesses" [16]. The sharing and re-use of sensitive and non-sensitive data of citizens and businesses demands for broad acceptance of this revolutionary concept by all stakeholders. 
To implement the once-only principle and to spur innovation, the European Commission has funded the SCOOP4C project (the sister project of TOOP) in the Horizon 2020 program [18], which focused OOP public services for citizens. The aims of SCOOP4C were a) to build up a stakeholder community for the once-only principle for citizens and b) to investigate, discuss and disseminate how the once-only principle can be implemented in contexts of co-creation and co-production of public services for citizens in order to contribute to significant administrative burden reduction [50, 58]. Along with the second aim, the project partners have systematically analyzed a number of OOP good practices. This contribution aims to summarize the findings from the good practice study of the SCOOP4C project. The main research questions are:

- What OOP good practice solutions exist in the Member States and across borders in the European Union?

- What enablers do exist in Member States, and what enablers need to be in place to enable OOP implementations at large?

In order to investigate these two research questions, structured qualitative case analysis and scenario technique were used. The remainder of the paper is as follows: The next section summarizes the theoretical and political foundations for the research, i.e. digitalization in the public sector and digital transformation with the OOP as a revolutionary concept. Subsequently, the methodical foundations outline the research design for the case study (Sect. 3). In Sect. 4, an overview of OOP good practice examples is provided and individual examples are briefly outlined. Based on the insights from the good practices, Sect. 5 discusses insights on the benefits for stakeholders as well as necessary enablers to widely implement the OOP across Europe. The conclusions sum up the findings and reflect further research needs.

\section{Theoretical and Political Foundations of the OOP}

Public sector digitalization is on the agenda of research for several decades. Its focus evolved and changed along the social, economic, political, technical and other challenges the public sector is exposed to over time. Likewise, the readiness of public institutions to transform themselves impacted its characteristics and success [41]. Subsequently, we therefore briefly summarize the evolution of digitalization and of digital transformation in the public sector.

The use of innovative information and communication technologies (ICTs) is an integral part of modernization strategies of governments [30]. Nowadays, digital transformation characterizes this attempt of modernizing government and public service provisioning. Over two decades ago, this concept was coined as electronic government or digital government (both concepts evolved and are used synonymously). Many scholars expect that the use of ICTs in electronic or digital government (i.e. in the modernization of public service provisioning) helps realizing added value such as increased efficiency, effectiveness, openness, transparency and improved quality of service for citizens and businesses [3, 4, 7, 22, 27, 30, 35, 37, 39]. Public value, increased government responsiveness and openness are further value expectations [35]. 
A customer-centric approach conveys the proposition of creating value for society and economy. As the once-only principle demands that citizens and businesses will only have to provide certain standard information to the public agencies once, public authorities are in need to share and re-use sensitive and personal data to reduce administrative burden for citizens and businesses [16, 33, 34, 58, 59]. However, sharing and re-use of such data must be done with due respect of data protection regulations [19], as otherwise trustworthiness of public service provisioning would be hampered tremendously. Hence, trust is an essential ingredient in implementing the once-only principle. Furthermore, digital transformation is not a smooth process, and digital tools do not per se contribute to before mentioned success factors. Since the digital transformation in government is considered to be a quite complex endeavour, coordination and engagement concepts as well as overarching architectures to enable secure and trustworthy access to data and information in inter-agency information sharing are further success criteria [25, 27, 59].

As argued in the introduction, the implementation of the once-only principle in the European Union is a policy goal settled in the eGovernment Action Plan 2016-2020 [16] and one of the pillars of the Digital Single Market Strategy [17]. It has been reinforced in the "Tallinn Declaration" signed by the European Digital Ministers [20] in 2017. The Single Digital Gateway (SDG) Regulation [21] requires European Member States to build up and connect to a single European portal and infrastructure, through which citizens, businesses and public administrations can execute public services across borders with the OOP as underlying principle. To realize the SDG, a successful implementation of the once-only principle requires transfer and re-use of sensitive or personal data between government agencies across borders involving actors on different levels of a political system. To develop the necessary trustworthy cross-border architecture and organizational frameworks for the SDG, significant effort is put by the European Commission and by the Member States (e.g. the European-wide projects TOOP [53] and DE4ALL [8]). TOOP developed a trust architecture [28, 44].

To implement interoperable data and information sharing, the European Interoperability Framework (EIF) provides a conceptual model for public services and considers data-related services as a basic component for service provision [14]. The SCOOP4C and TOOP projects rely on this EIF to structure their investigations of barriers, enablers and architecture for a comprehensive OOP implementation.

As outlined along the review of academic and policy literature on the OOP implementation, the realization of the once-only principle turns out to be a complex endeavour, where a number of factors need to be aligned and coordinated. To gather insights from existing OOP implementations, the SCOOP4C project investigated good practice cases and enablers of the once-only principle. Before presenting insights into the good practice analysis, the next section outlines the methodical foundations for the analysis.

\section{Methodical Foundations}

The research design for investigating OOP good practice solutions in the Member States and across borders in the European Union, for eliciting barriers and enablers along such initiatives, and for extracting recommendations to successfully implement the OOP consisted of three steps: 
a) Analysis of relevant literature and policy documents as summarized in Sect. 2;

b) Analysis of OOP good practices across Europe (see Sect. 4), separated into OOP cases, and OOP enablers and building blocks;

c) Elicitation of gaps and lessons from the good practice analysis, and formulation of policy recommendations for successful OOP implementation (see Sect. 5).

The review of academic literature depicted the evolution of public sector modernization through ICT towards digital transformation and its added value. Furthermore, policy documents were studied to gather the political dimension of the OOP. A descriptive analysis [40, 43] approach was applied in step 1. The study of strategic documents and studies encompassed the EU eGovernment Action Plan 2016-2020 [16], theEU Digital Single Market strategy [17], the European Interoperability Framework [14], the EU General Data Protection Regulation [19], the study on "eGovernment and the Reduction of Administrative Burden" [24], and the study on "EU-wide digital Once-Only Principle for citizens and businesses" [6].

The OOP good practice analysis in step 2 embarked on case study methodology $[23,61]$. Based on initial literature and policy document analysis in step 1, the team developed in an iterative step a template for collecting information on the cases to be studied. Along this step, a distinction between OOP cases and OOP enablers was necessary, which resulted in the definitions as follows:

$O O P$ cases refer to the provision of public services, where the once-only principle is implemented. Processing, sharing and re-using of citizen related data is enabled within a network of services used by public administrations to access the relevant data stored in different registers and applications. Consequently, citizens do not need to repeatedly provide the same data to the authorities. Furthermore, OOP cases can be grouped along particular policy domains such as education, healthcare, moving, social protection, taxation, etc.

The implementation of the OOP in public services (c.f. OOP cases) is supported by a set of enabling components. Therefore, $O O P$ enablers are defined as crucial building blocks that support the implementation of OOP cases in different policy domains through e.g. central infrastructure components for sharing and re-using sensitive data, semantic and technical architecture and solutions building blocks, as well as organizational, legal and political enablers. The enablers reach a wider scope than cases as one enabler may support the implementation of many different OOP cases in different policy domains.

Based on this distinction of OOP cases and OOP enablers, two correlating templates evolved in the preparation of the case study analysis to describe each case and enabler in the same way to ensure comparability. Besides demographic data, the template collected information such as a short summary about the project, what the legal and political enablers are/were for the OOP project, what architecture the OOP case or OOP enabler is built upon, which actors are involved and in which role (data owner, data provider, data consumer), what data exchange logics is applied, and what type of data sharing is embodied, what socio-cultural factors and other soft factors might be relevant, and what are the lessons from the project [50]?

The identification of cases and enablers was an iterative process involving the community network of the experts in the project. For example, steering board members were 
asked to inform the project team about relevant OOP solutions, project members investigated their communities to identify OOP cases or OOP enablers. The next task in this step was to collect the relevant case study descriptions along the developed template. This was done on the one hand by conducting desk research and studying relevant information on the public websites of the projects or institutions. On the other hand, relevant contact persons were identified and these experts were asked to either fill in the data along the provided template themselves (this was provided as an online form over the project's stakeholder community site) or to perform an online interview with project staff that recorded the answers. In a next task, the data was quality-assured by persons of the project team other than those that recorded the data, and reviewed and updated the collected data if necessary. The review and quality-assurance of the data of OOP cases and enablers was in some cases iterated several times between the contact point of the case study and the project team. Finally, the quality-assured project descriptions were published on the project's knowledge base [50].

In a final task of step 2, the OOP cases were analyzed in regards to success factors and OOP enablers involved in the OOP cases. Furthermore, barriers to implement OOP solutions were studied and extracted from the cases. This task applied a systematic analysis of the OOP cases and enablers for which the data was collected. For the analysis of the cases and enablers, the European Interoperability Framework (EIF) [14] and the European Interoperability Reference Architecture [13] represented major sources to group barriers and enablers along the interoperability levels and along crucial factors fostering interoperability in public service provisioning. In particular, the conceptual model of public service provisioning in the EIF guided in determining different types of enablers. From the literature analysis and from initial case studies, crucial soft "enabling factors" for successful OOP implementation were added, such as motivators, benefits, public value, data protection and privacy, trust and transparency, socio-cultural influence factors, citizen-centered design or data quality [37, 58].

The identified barriers and enablers were the input to the third step, where gap analysis was conducted and policy recommendations were formulated. The project team applied scenario technique [31, 32, 36, 38, 48, 55] to develop ideal future cross-border OOP scenarios in the five domains that were selected for the gap analysis, roadmapping and policy recommendations (i.e. education, healthcare, moving, social protection, and taxation). Scenarios are narrative textual descriptions (structured or unstructured), which are complemented with a rich picture to illustrate a perceived view or understanding of a specific topic [5,31]. The future once-only principle scenarios in the cross-border context described how future interactions between governments and the corresponding stakeholders could look like, which tools, standards, and technologies could be used to share and reuse data, and what further soft enabling factors complemented a comprehensive view on the future OOP implementation.

The five future cross-border OOP scenarios were used in interactive workshops with the stakeholders to deliberate barriers and enablers, to understand the gaps, needs and benefits of implementing the OOP at large, and to formulate policy recommendations for the widest possible OOP implementation. A total of nine workshops were conducted in the period 2018-2019. Each workshop had around 15 to 30 participants and three to five scenarios were deliberated in respective group discussions. The participants came 
from academia, public administrations, businesses as well as students and NGOs acting as citizen representatives.

The results of the good practice analysis of OOP solutions are presented in the next two sections.

\section{OOP Good Practice Examples in Europe}

In the SCOOP4C project, 57 OOP cases and 34 OOP enablers were analyzed [50]. The next subsections provide an overview of the OOP cases and OOP enablers studied, along with an outline of examples of OOP cases in the five selected domains and of OOP enablers in the categories 'secure data exchange', 'OOP enabling infrastructure', as well as 'eID and trust services'.

\subsection{OOP Cases}

Table 1 provides an overview of the OOP good practice cases studied in the SCOOP4C project. ${ }^{1}$ It is important to point out that the list of OOP good practices is by no means an exhaustive list of existing OOP cases in Europe. Instead and as mentioned in Sect. 3, the cases were identified either by steering board members or project members via searches and own contacts or were recorded by experts from the OOP cases via the online template.

To provide more detailed insights on OOP good practices, the following four OOP cases are exemplified from different domains (more detailed information is provided in $[50,54])$ :

Austrian Birth Registration and Child Benefit (ALF). Before modernizing the birth registration and child benefit service, parents of a newborn had to interact with six different public agencies to carry out up to nine different public services along the registration of a newborn and application for child benefit. These processes have been streamlined and integrated based on the once-only principle. With the new process of ALF [2], parents visit only the Civil Registry Office (one stop) and they need not to bring along any documents to evidence data that is already in the hands of public administration, except a personal identification (passport or personal ID card). In the Civil Registry Office, all data to record the newborn is collected and entered into the relevant interacting registers, such as the central civil register (ZPR), central citizenship register (ZSR) and central residence register (ZMR). After the recording of data on the newborn by the Civil Registry Office, a notification is sent to the Social Security Institution to trigger the issuance of the healthcare card (e-Card) for the newborn. The Social Security Institution generates the unique healthcare number and issues the e-Card, which is then automatically sent to the parents of the newborn (no stop). Furthermore, the unique healthcare number is sent to the Tax Authority, who also received a notification from the Civil Registry Office about the registration of a newborn. The two notifications trigger the next step, the establishment of a record for child benefit by the Tax Authority. If any data is missing, this is collected from the parents. However, if all data is available,

\footnotetext{
${ }^{1}$ See detailed descriptions of the OOP cases under https://scoop4c.eu/casetable.
} 
Table 1. Overview of OOP cases studied in SCOOP4C

\begin{tabular}{|c|c|}
\hline Domain (\# of cases studied) & $\begin{array}{l}\text { Examples of OOP cases studied in SCOOP } 4 \mathrm{C} \\
\text { (cases marked in italic are summarized below) }\end{array}$ \\
\hline Citizenship, basic data and registration (18) & $\begin{array}{l}\text { Bulgarian guide for administrative assistance and } \\
\text { awareness (GAAA), Danish basic data program, } \\
\text { several Estonian registration and basic data } \\
\text { services (e-Census, Eesti.ee, Election } \\
\text { information system, Internet voting, e-PRIA, } \\
\text { Employment register, register of professions, } \\
\text { Smart road system, Sports registry), French } \\
\text { Dites-les-nous une fois, German refugee } \\
\text { digitalization system, Hellenic Citizen Registry, } \\
\text { Irish government portal Gov.ie, several Spanish } \\
\text { registration and basic data services (Address } \\
\text { change service, Verification system and data } \\
\text { query (EPS), Via Oberta) }\end{array}$ \\
\hline Healthcare (10) & $\begin{array}{l}\text { Austrian electronic health records (ELGA), } \\
\text { Bulgarian national council on prices and } \\
\text { reimbursement of medical products, several } \\
\text { Estonian health services (Central health } \\
\text { information system and patient portal, Digital } \\
\text { prescription, Doctor-doctor consultation, } \\
\text { e-Ambulance and time-critical health data, } \\
\text { Medical certificate, Medical digital image bank), } \\
\text { Italian online service portal - healthcare booking } \\
\text { system, e-Health service eZdravje in Slovenia }\end{array}$ \\
\hline Education (8) & $\begin{array}{l}\text { Higher Education Institution Application } \\
\text { Systems in the Netherlands (Studielink), Estonia } \\
\text { (EHIS and SAIS), Ireland (Central Application } \\
\text { Office), Portugal (LGDF), Spain (NISUE), UK } \\
\text { (UCAS), and the European Student Card (ESC) }\end{array}$ \\
\hline Taxation (6) & $\begin{array}{l}\text { Online tax filing systems in Austria } \\
\text { (FinanzOnline), Estonia (E-Tax), France, } \\
\text { Germany (pre-filled tax return), Greece } \\
\text { (TAXISnet) and UK (MTD) }\end{array}$ \\
\hline Social protection (5) & $\begin{array}{l}\text { Austrian birth registration and child benefit } \\
(A L F) \text {, Estonian Parental Benefit, French Revenu } \\
\text { de sulidarité active, Polish baby bonus Becikowe, } \\
\text { Tell us once in UK }\end{array}$ \\
\hline Mobility (3) & $\begin{array}{l}\text { Austrian-German } x \text {-trans.eu, Tallinn public } \\
\text { transport ticket system (Estonia), French } \\
\text { application for parking vignette }\end{array}$ \\
\hline
\end{tabular}


Table 1. (continued)

\begin{tabular}{l|l}
\hline Domain (\# of cases studied) & $\begin{array}{l}\text { Examples of OOP cases studied in SCOOP4C } \\
\text { (cases marked in italic are summarized below) }\end{array}$ \\
\hline Others (7) & Several Estonian services (Consumer Service \\
& Environment Data System, e-File system, \\
& e-Notary, Sports Registry, Veterinary and Food \\
& Board), French Attestation Légale, French \\
& e-bourgogne-franche-comté GIP \\
\hline
\end{tabular}

the parents need no interaction with the Tax Authority in order to receive the child benefit on a monthly basis (no stop).

In order to make this OOP case work, the necessary political commitment and legal grounds (revision of the Austrian Act for family benefits, several legal acts on digital public services and basic enablers) have been put in place. Furthermore, the collaborative processes and interactions among the base registers have been standardized. A core enabler is the Portalverbund, an architecture for secured and trusted access to data across different registers and applications based on the secure identification of employees in public service through eID (see brief description in Subsect. 4.2).

Through 'ALF', substantial administrative burden reduction is achieved for parents, as they have only to go once to the Civil Registry Office to register the newborn and change the family status, they have not to bring along a number of evidences for the process, and they can receive the healthcare card and family allowance without having to fill any application upon the birth of a child. Key benefits for the public administrations are streamlined and automated processes, higher quality of data since the data is accessed at the authentic sources, and higher satisfaction of citizens overall through better and faster public services.

Dutch Higher Education Institution Application System (Studielink). Studielink [10] is the common registration and enrollment portal for all non-private higher education institutions (HEIs) in the Netherlands, which supports the exchange of data between the current or prospective students and the HEIs. To enroll to a HEI, the student first identifies him- or herself in Studielink through the Dutch eID (DigID). Subsequently, personal and educational data is retrieved through the application from relevant authentic sources such as the education register (maintained by the Dutch Education Executive Agency/Ministry of Education) and the personal data registers (municipal personal records database (GBA) run by the Dutch municipalities). The student then checks the retrieved information, adds new data on the intended study program, and finally applies to the study program. The HEIs can then retrieve the relevant applications and further process them.

Relevant enablers of the case are the political commitment and issuance of relevant legal regulations such as the Higher Education Act or the Personal Data Protection Act. Furthermore, an overall architecture concept and the Dutch System of Base Registries enables the secure data exchange across registers and domain-specific applications. The Dutch eID service DigID is another enabler to provide secure authentication of users. 
Studielink offers significant burden reduction for students and higher education institutions. It also increases the quality of data, since the basic data is retrieved from the authentic sources while only new information is entered by the users.

Estonian Central Health Information System and Patient Portal (EHR). The EHR [11] is a central patient-oriented system in Estonia, where data about a person's health treatments is collected, such as a short overview about the visit, anamnesis, diagnoses, treatment, examinations and recommendations. The data is accessible for all clinicians who treat the patient; for doctors that need to see a patient's data - access is only possible with their personal ID-card; and for patients through the patient portal using their personal ID-cards to see their own data, to make declarations (e.g. organ donations), and to check their treatment bills, prescriptions and the logging of who has accessed the patient's data. The EHR is one of a number of healthcare systems in place in Estonia. It is linked through X-Road (see OOP enabler example outlined in the next subsection) to other patient and medical information systems like the Medical Images Bank, the Prescription Centre and healthcare provider systems.

The success of the OOP case builds on a number of enablers, such as legal acts and regulations to enable the OOP case, including relevant data security guidelines issued by the Estonian Data Protection Inspectorate. The relevant actors have been involved to define and harmonize the collaborative business processes such as agreed workflows in the procedures, standards, classifiers and domain-specific data models among the health professionals. Contractual agreements of all healthcare providers to participate in the OOP case and in the sharing and re-use of the patient data. As already pointed out before, xRoad is the core secure data exchange layer that enables confidential and legally binding data exchange in the OOP case. In addition, the Estonian Public Key Infrastructure and eID infrastructure (ISKE) provides - through IDcard, mobileID or digiID - secure and trusted access to the relevant data for patients, doctors and nurses. Semantic interoperability is ensured through the Estonian Catalogue of Public Sector Information (RIHA), which provides necessary metadata descriptions. To ensure access to the 'right' data, unique personal identification codes and unique company commercial registry codes have been established as well. Trust and transparency are established by enabling persons to view their prescriptions, summary reports, test results (except images) and the details of their children. The users can also see, who else has viewed their data in the systems. And they can decide to make their data accessible or inaccessible to doctors and other healthcare service providers, issue expressions of will (regarding organ donations, powers of attorney) and order electronic medical certificates.

The EHR case significantly reduces administrative burden for patients and the actors in the healthcare system, as all documents and data of a patient and his or her health history are available through the central system. With the central EHR system and its secure and trusted interconnectedness through xRoad, improved quality of medical service is provided, which in turn leads to higher satisfaction of citizens.

Greek Online Tax Filing System (TAXISnet). TAXISnet [29] is the integrated information system of the Hellenic tax system aiming to provide online electronic services to citizens and businesses through pre-filled forms and the collection of citizen data from employers (such as salary details), banks and other administrations to provide these data 
to other public authorities at a central point. The information system interconnects all tax departments in Greece with the central point and the respective databases, and it has probably the largest number of users of public sector information systems in Greece. TAXISnet offers personalized information to citizens and businesses through its portal, as well as by sending automated emails. The registration to the service is a simple procedure. After the registration to the service, citizens or businesses are informed regularly by SMS on the tax that they have to pay and by when the payments are due. Recent amendments of the TAXISnet solution towards further OOP implementations are the confirmation of a person's details, the tax registration data, certificates that a person or a company do not have any debts relevant to tax (relevant e.g. in public procurement procedures), certification for any debts of a person or a company to any public-sector organization, or the provision of vehicle owner details at a specific point of time.

A crucial enabler is the Interoperability Centre of the Ministry of Finance, which provides a set of web services to public administrations to get access to relevant data of citizens and businesses, which is in the hands of other public administrations in Greece.

The main benefits of this case are for citizens to receive proactive services and notifications on relevant taxes to be paid and other certifications needed in public services. Public administrations are supported in the execution of their tasks by web services to access relevant data from authentic sources.

\subsection{OOP Enablers}

In Table 2, the OOP good practice enablers studied in SCOOP4C ${ }^{2}$ are grouped along six categories. Like for the OOP cases, this list does by no means provide an exhaustive list of existing OOP enablers in Europe. The enablers were either identified in the same way as the OOP cases (see indication at the beginning of Subsect. 4.1) or these were spotted along the data collection on OOP cases.

The following four examples provide more detailed insights into good practice enablers of secure data exchange and enabling infrastructure (more detailed information is provided in [50, 54]):

Dutch Basisregistraties. Basisregistraties [9] were established in the Netherlands to store all vital data about citizens, businesses and institutions in a centralized manner. In total, ten basis registries have been officially instated to implement the once-only principle in public service provisioning (addresses and buildings, geographical information and maps, topography, income registry for taxation, cadasters and real estate property, reference property values, environment and surface, citizens, companies, vehicles). These are mandatory data registration sources for all governmental institutions when executing their public duties. To enable the secure data exchange among these base registries and applications in the Netherlands, several core building blocks were set up as well: a) Digidelivery as the electronic delivery service enables public administrations and businesses to quickly and efficiently exchange data among key register clients in the shape of event messages; b) Digilink offers standards for interfaces, including agreements, for the exchange of data between public authorities. Digilink therewith enables to connect

\footnotetext{
${ }^{2}$ See detailed descriptions of the OOP enablers under https://scoop4c.eu/enablertable.
} 
Table 2. Overview of examples of OOP enablers studied in SCOOP4C

\begin{tabular}{l|l}
\hline Category (\# of enablers studied) & $\begin{array}{l}\text { Examples of OOP enablers studied in SCOOP4C (enablers } \\
\text { marked in italic are summarized below) }\end{array}$ \\
\hline Secure Data Exchange (12) & $\begin{array}{l}\text { Belgian MAGDA, Czech Basic Registers, Dutch } \\
\text { Basisregistraties, Estonian X-Road, European-wide ECRN, } \\
\text { European-wide ECRIS, European-wide EESSI, European } \\
\text { EMREX, European-wide EURCARIS, Spain's PID-SVD, } \\
\text { Spain's SIR, Spain's SPD }\end{array}$ \\
\hline Enabling Infrastructure (10) & $\begin{array}{l}\text { Network of public authorities in Austria (Portalverbund), } \\
\text { European-wide BRIS, Greek's SYZEFXIS, Irish } \\
\text { Government Network, Luxemburg's my Guichet, Portugal's } \\
\text { iAP, Spanish SEDIPUALB @, Spanish InSide, Spanish } \\
\text { CONSERVATIONISTS, Spanish Red SARA }\end{array}$ \\
\hline eID and Trust Services (6) & $\begin{array}{l}\text { PKI and ISKE in Estonia, PKI in Greece, Irish MyGovID, } \\
\text { Irish Public Service Card, Spanish PKI Suite @ firma }\end{array}$ \\
\hline Interoperability Governance (3) & $\begin{array}{l}\text { Greek and Spanish Interoperability Models, Argentinian } \\
\text { Interoperability Model }\end{array}$ \\
\hline Interoperability Assets (2) & German xAusländer, Irish Personal Public Service Number \\
\hline Catalogue (1) & Estonian Catalogue of Public Sector Information (RIHA) \\
\hline
\end{tabular}

nearly all e-government building blocks set up in the Netherlands; c) Diginotification is a notification tool to guarantee the quality of data in the key registries to be up-to-date and reliable; d) NORA as the Netherlands Government Reference Architecture provides an overall framework and existing agreements for the Dutch governmental information management system to ensure smooth cooperation with other services, and optimal reuse of existing solutions; and finally e) a System Catalogue, which make the data in the base registries findable and reachable.

The use of the Basisregistraties in the Netherlands offers a variety of benefits including reduction of administrative burdens for citizens and businesses as they do not need to provide information again that is already in the hands of government. The government can operate more efficiently and improve quality of services that government organizations such as public health services or fire stations deliver.

Estonian X-Road. X-Road [12] is a technical and organizational environment enabling secure data exchange between various information systems in Estonia. Security is provided through authentication, multilevel authorization, a high-level log processing, as well as encrypted and time-stamped data traffic. Public and private sector institutions can connect their decentrally organized information systems with the central component X-Road. X-Road can be considered as a federation with the capability to provide secure Internet-based data exchange across different ecosystems. Every X-Road environment is managed by a competent organization (center) that defines the applied security policy and manages the information of its ecosystem members. The federation agreement 
entails the description of organizational and legal liabilities between the centers of different ecosystems, which allows databases to interact and make integrated e-services possible, and institutions not to be locked into any one type of database or software provider. Some underlying components of the X-Road enabler are a) the unique personal identification code that is needed to identify the right personal data from different registers; b) the unique company commercial registry code that is needed to identify the right business data from different registers; and c) the catalogue of services and data (RIHA), which provides metadata on registers and services to be findable and usable.

$\mathrm{X}$-Road enables institutions to save resources and implement significantly more efficient services, since a cooperative and secure data exchange layer is provided to all members that have signed the agreement.

Network of Public Authorities in Austria (Portalverbund). The Austrian Portalverbund [1] enables different government portals to team up with each other to simplify the authentication of users that have already been authenticated via another trusted portal in the government network. This way, the portal group building block connects many applications from a single entry point (the starting portal of a user) and realizes the single sign on concept. Communication within the portal group is managed, both technically and organizationally, through the portal group protocol (PVP) and the use of security classes. Application providers determine which of their applications will be available over which portals. Keeping in accordance with all data protection regulations, they specify which administration units and employees are authorized to access which applications and define user roles with corresponding access rights.

The Portalverbund targets employees of public administrations and simplifies the access to the various authentic sources and e-government applications in the Austrian e-government applications with the purpose to simplify and enable the benefits of the OOP to be realized for citizens and businesses.

Spanish Red SARA. The Spanish Public Administration telecommunications networks are organized hierarchically based on the Spanish territorial sovereignty (network of municipalities of a certain region, network of regions, network of Ministries). Because governments need to interact and collaborate over the different federal levels, a secure and reliable interchange of information among all levels of government was set up, the Red SARA (or SARA network - System of applications and connections of public administrations) [51]. Red SARA is a set of telecommunications infrastructure and basic common services (such as e-signature validation, verification of identity and residence data, e-notification) that supports the interconnection and the interoperability of all existing Spanish Public Administration networks. It facilitates the sharing of information and services between public administrations over all federal levels in Spain and it interconnects to institutions in Europe and other European Member States through sTESTA [15].

The benefits of Red SARA are the independence of Spanish Public Administrations in their own infrastructure setup, while they can easily connect and interact with other institutions at the different federal levels over the commonly agreed interfaces and interoperability features. This way, the once-only principle can be implemented in public service provisioning, leading to simplification and reduction of administrative 
burdens for citizens and businesses, while at the same time maintaining the autonomy of government actors in the federal system.

\section{Discussion and Recommendations from the Good Practices}

The previous section outlined good practices of OOP cases and OOP enablers in European Member States. In order to consider an OOP case or OOP enabler a good practice and a success, the benefits of OOP implementations as well as the barriers and enablers in cross-border OOP public services need to be understood well. Both are synthesized and derived from the case studies and from literature analysis, and described in the following.

\subsection{Benefits of OOP Implementation and the Need for OOP Enablers}

As already outlined in Sect. 2 and along the description of OOP cases and enablers in the previous section, the once-only principle embodies a number of benefits to the actors involved. These are summarized below along the main benefits identified both in literature (see e.g. $[6,16,20,21,24,33,34,49,54,58]$ ) and demonstrated in the OOP examples ALF, EHR, Studielink and TAXISnet outlined in Sect. 4. In addition to the benefits for targeted stakeholders, needed OOP enablers to realize the benefits are spotted.

Reduction of Administrative Burden. The once-only principle contributes to administrative burden reduction in various ways as:

a) citizens and businesses need not to provide the same data repeatedly along public service provisioning. To render the public service providers as data consumers to access data that they need in public service provisioning from data providers, relevant OOP enablers such as secure data exchange mechanisms, interoperability assets and enabling infrastructures need to be in place.

b) public service providers benefit from simplified, less cumbersome and more convenient procedures and pro-active public service offers alike, as they can access and re-use data from the authentic sources through secure enabling infrastructure.

Increased Transparency and Trust. By realizing the concept of consent for sharing and reusing data on respective data subjects (citizens or businesses), the once-only principle contributes to higher trust and transparency in public service, since data subjects can verify (e.g. through a user account and through particular logging mechanisms, etc.) the compliant use of their data and they can have better control over their data. This mechanism is e.g. implemented along the Estonian OOP infrastructure X-Road. In the TOOP project, such mechanism is conceptualized and implemented as well.

Increased Efficiency and Effectiveness. The wide implementation of the OOP contributes to increased efficiency and effectiveness of public administration through cocreation and collaboration between administrations by opening up, sharing and re-using 
knowledge and resources with the aim to unlock productivity improvements and foster the creation of more public value. Providing access to relevant data also enables public service providers to pro-actively offer public services to citizens as is demonstrated in the ALF OOP case outlined above. Along with the proactive service provisioning, the sharing and re-use of data across public service providers enables governments to fulfill legal obligations faster. Such efficiency gains are clearly recognizable in the OOP cases studied in SCOOP4C $[49,54]$ and exemplified in the OOP cases in Subsect. 4.1 above.

Higher Quality of Data. Another core benefit for public administrations in the OOP implementation is that enablers such as secure data exchange, eID and trust services as well as enabling infrastructures offer access to quality-assured authentic sources of data. In combination with the reduction of administrative burden and more efficient and effective process execution, public administration are facilitated to save costs and to reduce redundant and error-prone activities of repeated recording of data that is already in the hands of public administration, as the data is retrieved from the quality-assured authentic sources. In addition, the recording of new or revised data is done once. In many cases, this step is even assigned to the data subject (i.e. citizens and businesses) through online service portals.

\subsection{Enablers as a Vehicle to Overcome Barriers of OOP Implementations}

In order to realize the benefits of the once-only principle for citizens and businesses as well as for public service providers, a number of key enablers have to be in place. In the SCOOP4C project, we argue that barriers and enablers of OOP implementations are two sides of the same coin: while the barriers represent obstacles and hindrances that prevent the realization of the OOP in public service provisioning, the enablers help to overcome these barriers and to guarantee the widest possible success in leveraging the benefits of the once-only principle. In other words, governments need to put in place the respective enablers to ensure the successful and effective implementation of the once-only principle.

Along the good practice analysis and subsequent roadmapping activity in SCOOP4C, the subsequent enablers of OOP implementations have been identified and elaborated. Since barriers of OOP are considered the non-availability of enablers, only the positive side of the coin (i.e. existing enablers) is considered below. The categorization of enablers is on the one hand derived from the interoperability layers of the European Interoperability Framework and the conceptual model of public services in the EIF [14], the European Interoperability Reference Architecture (EIRA) [13]. On the other hand, further soft factors are grouped into relevant categories as outlined in Sect. 3.

The following core enablers of successful OOP implementations have been grouped along the interoperability layers and concepts of the public service conceptual model of the EIF:

Political Commitment. Political commitment is considered a pre-condition for successful OOP implementations and is particularly stressed at European level through strategic documents such as the EU eGovernment Action Plan 2016-2020 [16], the 
Single Digital Market Strategy for Europe [17], the Single Digital Gateway Regulation [21] or the EIF [14]. Many EU Member State countries have corresponding digitalization strategies incorporating the once-only principle as a strategic priority. Integrating the implementation of the once-only principle in digitalization strategies at the different levels of Government in Europe is a key enabler. An essential aspect along such political commitments are the will and capacities of governments to finance, coordinate, implement, and monitor the realization of the once-only principle in public service provisioning. To boost innovation and to respect different maturity levels across Europe, the implementation of the OOP in public service may first be based on coalitions of the willing actors and therewith also boost competition in being the first and best practice.

Legal Frameworks. Legal frameworks are required to enable the sharing and reuse of data stored in government's base registries while at the same time ensuring data privacy and protection of citizen's rights. Hence, legal frameworks have to be scrutinized and adjusted to enable the once-only principle to be realized in public service provisioning. Particular areas, where regulations represent key enablers for the sharing and re-use of sensitive data, concern e.g. the many base registries of the public sector, secure data exchange mechanisms, eID and trust services, as well as data protection and data privacy. The European Union has provided such crucial legal enablers such as the General Data Protection Regulation [19] or the Single Digital Gateway Regulation [21]. The same applies to the Member State countries. For example, to enable the OOP solutions ALF, Studielink, EHR and TAXISnet presented in Sect. 4, necessary legislation has been put in place in Austria, Estonia, Greece and the Netherlands.

Organizational Commitment and Collaborative Business Processes. Besides the legal framework, organizational commitment and collaborative business processes have to be in place to enable governments to share citizens' (personal) data among public administrations in secured networks (i.e. sharing and re-using knowledge assets e.g. stored in base registries) and on the basis of standards. The OOP cases outlined in Sect. 4.1 build on such commonly agreed collaborative business processes. Another organizational enabler is multilateral agreements to collaborate as well as to use open standards and open specifications in the public service provisioning implementing the OOP. Such agreements should also be in place regarding the use of common technical infrastructure.

\section{Ensuring Semantic Interoperability Through Common Data Exchange Standards, Common Vocabularies and Taxonomies. Data exchange across different institutions requires semantic enablers to be in place, such as standards for the data exchange, a common terminology, controlled vocabularies and agreed-upon code lists (e.g. as unique identifiers of data sets), or taxonomies to facilitate data exchange between different institutions. The secure data exchange enablers introduced in Sect. 4.2 above present such examples.}

Technical Enablers such as Secure Networks and Infrastructure. Commonly used secure networks and infrastructure are key enablers for the interchange and re-use of citizens' data across the governments, including across borders. This includes commonly used services for electronic identification and for trust services (e.g. concept of active 
consent) as well as commonly used solutions for secure and trusted enabling infrastructure such as e-delivery building block. Examples from the SCOOP4C case study are described in Sect. 4.2.

Collaborative Governance Mechanisms. The implementation of the once-only principle demands different institutional actors to collaborate among different stakeholders. To facilitate the successful implementation of the once-only principle, appropriate collaborative governance models are needed, which clearly define the responsibilities and roles of actors on different levels of governance. Of particular relevance are interoperability governance and public service governance, which both need to be aligned as spotted in $[13,54,57,59]$.

Beyond the key enablers clustered on the basis of the EIF, the following crucial soft enabling factors have been identified and synthesized from the case study analysis:

Motivators, Benefits, and Public Value. Providing incentives, benefits, public value or convenience for citizens, businesses and governments to share and re-use data stored in public administrations' registries is the first soft key enabler to mention. The OOP case examples outlined in Sect. 4.1 demonstrate clearly these motivators and benefits to the relevant stakeholders. This contributes to better acceptance and use of the OOP solution.

Access to Authentic Sources Contributes to Improved Data Quality. The access to authentic data contributes to increased data quality in governmental registries. This enabler can be achieved through the implementation of enablers such as secure data exchange and enabling infrastructure and the necessary interoperability enablers outlined before and some examples provided in Sect. 4.2. Great examples that demonstrate the value-added of improved data quality realized through direct access to authentic sources are the OOP cases presented in Sect. 4.1.

Trust and Transparency. Trust and transparency mechanisms enable citizens to control and monitor by whom, when, and why their data is accessed. Such enabling building blocks are for example the concept of active consent for the sharing and re-use of sensitive or personal data of citizens and businesses or the access to the logging of who has accessed data on the data subject in a particular registry, by when and for what purpose. Such a service is e.g. provided via the X-Road enabler in Estonia (cf. enabler description in Sect. 4.2).

Data Protection and Privacy. The sharing and re-use of citizen data requires to respect privacy and ensure data protection. Hence, mechanisms for data protection need to be in place. Such mechanisms can be on the one hand relevant legislation as is outlined in the respective legal framework enabler above as well as technical building blocks such as eID and trust services such as the concept of the consent (see next enabler) or secure data exchange or infrastructure building blocks.

Socio-cultural Influence Factors. Socio-cultural aspects such as traditions of sharing or not sharing data among governments, ownership of data and citizens' obligations vs. freedom of deciding when and how to provide data to governments are central for 
gathering acceptance of the once-only principle by citizens and businesses. In some countries, the data stored only for special purposes means that this data is not usable beyond the given constitutional and legal frame, organizational settings and cultural restrictions, thus limiting the OOP implementation to the scope of the service and data. Such factors may vary across countries. However, they play a crucial role in the public service provisioning and in ensuring acceptance and trust of citizens and businesses in the public service.

Citizen-Centered Design. To correspond to the needs and expectations of citizens and other stakeholders in the OOP implementation in the best possible was, the relevant actors need to be involved in co-designing and co-developing of the OOP services, ensuring ease of use, convenience, and good user experience. The more citizen-centered the design of public services is, the more it enables the creation of better quality policy decisions and the offering of better services in the future.

It is important to note that the different enablers outlined above are not mutually exclusive. Instead, the enablers build upon one another and are therefore intertwined and mutually dependent. This means that just implementing one of the enablers is not sufficient for a successful implementation of OOP solutions.

\section{Conclusions}

This contribution investigated the implementation of the OOP across Europe by studying existing good practice cases and enablers in different Member States. First, an overview of relevant theoretical and political foundations was provided, followed by an outline of the research design, which employed literature analysis and case study research. The presentation of good practices is divided into OOP cases and OOP enablers. In the SCOOP4C project, 57 OOP cases and 34 OOP enablers were analysed. Four examples per group were briefly outlined in the paper to demonstrate how the OOP is realized and provides benefits to citizens and public sector actors.

Subsequently, a synthesis of benefits and key enablers to realize the once-only principle widely was presented. The benefits affiliated with OOP implementations in public service provisioning are a) reduction of administrative burden, b) increased trust and transparency, c) increased efficiency and effectiveness, and higher quality of data. Eleven key enablers of OOP implementations were spotted: 1) political commitment, 2) legal frameworks, 3) organizational commitment and collaborative business processes, 4) semantic interoperability through common data exchange standards, common vocabularies and taxonomies, 5) technical enablers such as secure networks and infrastructure, 6) collaborative governance mechanisms, 7) motivations, benefits, and public value, 8) Access to authentic sources to improve data quality, 9) trust and transparency, 10) data protection and privacy, and 11) citizen-centred design.

The research stressed that barriers and enablers of OOP implementations form linked concepts, i.e. a barrier indicates a lack (or absence) of what is, in the positive formulation, an enabler. For example, a barrier at political level was identified in SCOOP4C as the "lack of political commitment to enforce and implement fully digital procedures in student exchange across Europe" while the complementary enabler would be a "strong political 
commitment to implement the digital procedures in student exchange services across Europe" [49].

To sum up the findings from the OOP good practice analysis, the investigation has evidenced existing good practice cases and enablers in different Member States. However, the diffusion of OOP solutions is still scarce, especially at cross-border levels of OOP solutions. Further research and efforts from the side of government actors are needed to successfully implement the OOP across borders. The TOOP project provides a great federated architecture $[28,44]$ for enabling the provision of OOP solutions across borders. This architecture is picked up and further developed in the DE4ALL project [8]. However, as the analysis of good practices has shown, the success of the OOP implementation depends on many different enablers. Putting such enablers in place demands further considerable effort along a holistic perspective on public service design and implementation with the OOP.

Some further general insights from the above research can be summarized as follows:

- While strategic policies in Europe extensively promote digitalization, networked systems and interoperability, digital transformation in practice and with the OOP as underlying paradigm is considerably lagging behind these visions.

- While OOP visions are promoted to create awareness of the potentials and benefits, these activities are not necessarily reaching out to those that in the end have to implement the OOP solutions.

- In particular, top-down implementation of digitalization needs to urgently be complemented with bottom-up engagement of relevant stakeholders by employing e.g. co-creation concepts, stakeholder engagement and similar to involve the relevant stakeholders in such digital transformations.

- Attempts of bottom-up stakeholder engagement to realize interoperable cross-border public services need be complemented with qualitative research to systematically and rigorously understand barriers and challenges of actors in digital public service provisioning and to design OOP solutions that meet the users' expectations.

\section{References}

1. Austrian Portalverbund. https://neu.ref.wien.gv.at/at.gv.wien.ref-live/web/reference-server/ ag-iz-portalverbund. Accessed 01 Sept 2020

2. Austria's Antraglose Familienbeihilfe. https://www.brz.gv.at/was-wir-tun/services-produkte/ no-one-stop-shops/antraglose-familienbeihilfe.html. Accessed 01 Sept 2020

3. Brown, M., Brudney, J.: Achieving advanced electronic government services: an examination of obstacles and implications from an international perspective. In: Paper presented at the 6th National Public Management Research Conference, Bloomington, IN (2001)

4. Bellamy, C., Taylor, J.A.: Reinventing government in the information age [electronic resource]: international practice in IT-enabled public sector reform. Public Money Manag. 14(3), 59-62 (1994)

5. Carroll, J.: Scenario-Based Design: Envisioning Work and Technology in System Development. Wiley, New York (1995) 
6. Cave, J., Botterman, M., Cavallini, S., Volpe, M.: EU-wide digital Once-Only Principle for citizens and businesses. Study for the European Commission (2017). https://ec.europa.eu/esf/ transnationality/filedepot_download/1671/1692. Accessed 24 Oct 2020

7. Cordella, A., Bonina, C.M.: A public value perspective for ICT enabled public sector reforms: a theoretical reflection. Gov. Inf. Q. 29(4), 512-520 (2012)

8. DE4ALL - Digital Europe for All. https://cordis.europa.eu/project/id/870635. Accessed 11 Oct 2020

9. Digital Government - Dutch Base Registries. https://www.nldigitalgovernment.nl/dossiers/ base-registers-and-system-standards/. Accessed 30 Oct 2020

10. Dutch Studielink. https://www.studielink.nl/. Accessed 01 Oct 2020

11. Estonian central health information system and patient portal (EHR). https://www.digilugu.ee. Accessed 31 Oct 2020

12. Estonian X-Road. https://www.ria.ee/en/state-information-system/x-tee.html. Accessed 01 Oct 2020

13. European Commission: European Interoperability Reference Architecture and Cartography tool, ISA ${ }^{2}$ - Interoperability solutions for public administrations, businesses and citizens. https://ec.europa.eu/isa2/solutions/eira_en. Accessed 24 Oct 2020

14. European Commission: New European Interoperability Framework - Promoting Seamless Services and Data Flows for European Public Administrations. Publications Office of the European Union, Luxemburg (2017)

15. European Commission - ISA ${ }^{2}$ : Strengthening the EU's telecommunications backbone. https://ec.europa.eu/isa2/actions/strengthening-eu\%E2\%80\%99s-telecommunications-bac kbone_en. Accessed 31 Oct 2020

16. European Union: EU eGovernment Action Plan 2016-2020 - Accelerating the Digital Transformation of Government. COM/2016/0179 final, Brussels (2016)

17. European Union: A Digital Single Market Strategy for Europe. COM (2015) 192 Final. https:// eur-lex.europa.eu/legal-content/EN/TXT/?uri=celex\%3A52015DC0192

18. European Union: Horizon 2020 funding programme: Europe in a changing world - Inclusive, innovative and reflective societies. http://ec.europa.eu/programmes/horizon2020/nod e/85. Accessed 04 Oct 2020

19. European Union: Regulation 2016/679 of the European parliament and the Council of the European Union: General Data Protection Regulation. Official Journal of the European Communities (2016). https://eur-lex.europa.eu/eli/reg/2016/679/oj

20. European Union: Tallinn Declaration on eGovernment at the Ministerial Meeting during Estonian Presidency of the Council of the EU (2017). https://ec.europa.eu/newsroom/doc ument.cfm?doc_id=47559. Accessed 04 Oct 2020

21. European Union: Regulation 2018/1724 of the European Parliament and of the Council on establishing a single digital gateway to provide access to information, to procedures and to assistance and problem-solving services. Official Journal of the European Communities (2018). https://eur-lex.europa.eu/legal-content/EN/TXT/?uri=uriserv:OJ.L_.2018.295. 01.0001.01.ENG.

22. Fang, Z.: E-government in digital era: concept, practice, and development. Int. J. Comput. Internet Manag. 10(2), 1-22 (2002)

23. Gagnon, Y.-C.: The CASE STUDY as Research Method: A Practical Handbook. Presses de l'Université du Québec, Quebec City (2010)

24. Gallo, C., Giove, M., Millard, J., Valvik Thaarup, R. K.: Study on eGovernment and the Reduction of Administrative Burden. Final Report, European Commission, DG CNECT (2014). https://doi.org/10.2759/42896 
25. Gil-Garcia, J.R., Guler, A., Pardo, T.A., Burke, G.B.: Characterizing the importance of clarity of roles and responsibilities in government inter-organizational collaboration and information sharing initiatives. Gov. Inf. Q. 36(4), 101393 (2019). https://doi.org/10.1016/j.giq.2019. 101393

26. Gil-Garcia, J.R., Martinez-Moyanoc, I.J.: Understanding the evolution of e-government: the influence of systems of rules on public sector dynamics. Gov. Inf. Q. 24(2), 266-290 (2007)

27. Gil-Garcia, J.R., Sayogo, D.S.: Government inter-organizational information sharing initiatives: understanding the main determinants of success. Gov. Inf. Q. 33(3), 572-582 (2016)

28. Grandy, E., et al.: Generic Federated OOP Architecture. TOOP Consortium (2018). http:// www.toop.eu/sites/default/files/D22_Generic_Federated_OOP_Architecture_Final.pdf

29. Greek's TAXISnet. https://www.gsis.gr/. Accessed 31 Oct 2020

30. Janowski, T.: Digital government evolution: from transformation to contextualization. Gov. Inf. Q. 32(3), 221-236 (2015)

31. Janssen, M., et al.: Scenario building for e-government in 2020: consolidating the results from regional workshops. In: Proceedings of the 40th Annual Hawaii International Conference on System Sciences (HICSS-40), IEEE Computer Society, Washington (DC), Digital Proceedings (2007)

32. Janssen, M., van der Duin, P., Wimmer, M.: Methodology for scenario building. In: Codagnone, C., Wimmer, M.A. (eds.): Roadmapping eGovernment Research. Visions and Measures towards Innovative Governments in 2020, pp. 21-27 (2007)

33. Kalvet, T., Toots, M., van Veenstra, A.F., Krimmer, R.: Cross-border e-government services in Europe: expected benefits, barriers and drivers of the once-only principle. In: Proceedings of the 11th International Conference on Theory and Practice of Electronic Governance (ICEGOV2018), pp. 69-72 (2018)

34. Krimmer, R., Kalvet, T., Toots, M., Cepilovs, A., Tambouris, E.: Exploring and demonstrating the once-only principle: a European perspective. In: Proceedings of the 18th Annual International Conference on Digital Government Research, pp. 546-551 (2017)

35. Lindgren, I., van Veenstra, A.F.: Digital government transformation: a case illustrating public e-service development as part of public sector transformation. In: Proceedings of the 19th Annual International Conference on Digital Government Research, Article No. 38 (2018). https://doi.org/10.1145/3209281.3209302

36. Lob, G., Costa, S., Nogueira, R., Antunes, P., Brito, A.: A scenario building methodology to support the definition of sustainable development strategies: the case of the Azores Region. In: 11th Annual International Sustainable Development Research Conference (2005)

37. Luna-Reyes, L.F., Mellouli, S., Bertot, J.C.: Key factors and processes for digital government success. Inf. Polity 18(2), 101-105 (2013)

38. Majstorovic, D., Wimmer, M.: Future scenarios of ICT solutions for governance and policy modelling. In: Proceedings of ICEGOV 2014, ACM, Digital Proceedings (2014)

39. Milakovich, M.E.: Digital Governance: New Technologies for Improving Public Service and Participation, 1st edn. Routledge, New York (2012)

40. Müller-Bloch, C., Kranz, J.: A framework for rigorously identifying research gaps in qualitative literature reviews. In: Proceedings of Thirty-Sixth International Conference on Information Systems (2015)

41. OECD: Recommendation of the Council on Digital Government Strategies. Public Governance and Territorial Development Directorate (2014). https://doi.org/10.1007/s13398-0140173-7.2

42. OECD: Data-Driven Innovation: Big Data for Growth and Well-Being. OECD Publishing, Paris (2015). https://doi.org/10.1787/9789264229358-en

43. Paré, G., Trudel, M.-C., Jaana, M., Kitsiou, S.: Synthesizing information systems knowledge: a typology of literature reviews. Inf. Manag. 52(2), 183-199 (2015) 
44. Pavleska, T., Aranha, H., Masi, M., Grandy, E., Sellitto, G.P.: Cybersecurity evaluation of enterprise architectures: the e-SENS case. Proc. PoEM 2019, 226-241 (2019)

45. Pereira, G.V., Parycek, P., Falco, E., Kleinhans, R.: Smart governance in the context of smart cities: a literature review. Inf. Polity 23(2), 143-162 (2018)

46. Pucihar, A., Bogataj, K., Wimmer, M.: Gap Analysis Methodology for Identifying Future ICT Related eGovernment Research Topics - Case of "Ontology and Semantic Web" in the Context of eGovernment. AIS Electronic Library (2007)

47. Rosenbaum, S.: Data governance and stewardship: designing data stewardship entities and advancing data access. Health Serv. Res. 45(5), 1442-1455 (2010)

48. Rotmans, J., et al.: Visions for a sustainable Europe. Futures 32, 809-831 (2000)

49. Roustaei, A., et al.: Gap analysis report of challenges, needs and benefits of the OOP4C analysis. SCOOP4C Consortium (2019). https://scoop4c.eu/sites/default/files/2019-06/SCO OP4C_D4.1_v1.1.pdf. Accessed 04 Oct 2020

50. SCOOP4C - Stakeholder Community for the Once-Only Principle for Citizens project. https:// scoop4c.eu/. Accessed 04 Oct 2020

51. Spanish Red SARA. https://administracionelectronica.gob.es/ctt/redsara?idioma=en. Accessed 05 Sept 2020

52. Stocksmeier, D., Wimmer, M.A., Führer, M., Essmeyer, K.: Once-only in Deutschland und Europa: Eine Roadmap grenzüberschreitender Vernetzung im Bereich Steuern. In: Digitalisierung von Staat und Verwaltung, 87-98 (2019)

53. TOOP - The Once-Only Principle project. https://toop.eu/. Accessed 11 Oct 2020

54. Vallner, U., et al.: State of play report of best practices. SCOOP4C Consortium (2017). https:// scoop4c.eu/sites/default/files/2018-01/SCOOP4C_D1.2_0.pdf. Accessed 01 Oct 2020

55. van Notten, P., Rotmans, J., van Asselt, M., Rothman, D.: An updated scenario typology. Futures 35(5), 423-443 (2003)

56. Weerakkody, V., Janssen, M., Dwivedi, Y.K.: Transformational change and business process reengineering (BPR): lessons from the British and Dutch public sector. Gov. Inf. Q. 28(3), 320-328 (2011)

57. Wimmer, M.A., Boneva, R., di Giacomo, D.: Interoperability governance: a definition and insights from case studies in Europe. In: Proceedings of the 19th Annual International Conference on Digital Government Research: Governance in the Data Age, ACM (2018). https:// doi.org/10.1145/3209281.3209306

58. Wimmer, M.A., Marinov, B.: SCOOP4C: reducing administrative burden for citizens through once-only - Vision \& challenges. Jusletter IT (2017)

59. Wimmer, M.A., Neuroni, A.C., Frecè, J.T.: Approaches to good data governance in support of public sector transformation through once-only. In: Viale Pereira, G., et al. (eds.) EGOV 2020. LNCS, vol. 12219, pp. 210-222. Springer, Cham (2020). https://doi.org/10.1007/9783-030-57599-1_16

60. Yildiz, M.: E-government research: reviewing the literature, limitations, and ways forward. Gov. Inf. Q. 24(3), 646-665 (2007)

61. Yin, R.K.: Case Study Research and Applications: Design and Methods, 6th edn. Sage Publications Inc., New York (2018) 
Open Access This chapter is licensed under the terms of the Creative Commons Attribution 4.0 International License (http://creativecommons.org/licenses/by/4.0/), which permits use, sharing, adaptation, distribution and reproduction in any medium or format, as long as you give appropriate credit to the original author(s) and the source, provide a link to the Creative Commons license and indicate if changes were made.

The images or other third party material in this chapter are included in the chapter's Creative Commons license, unless indicated otherwise in a credit line to the material. If material is not included in the chapter's Creative Commons license and your intended use is not permitted by statutory regulation or exceeds the permitted use, you will need to obtain permission directly from the copyright holder.

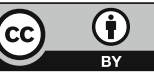

